tional properties of the regenerated mesothelium-like cells that could better stimulate and facilitate the absorption. We believe that adhesion formation and functional activity of the regenerated tissue onto the PHB patch should be reevaluated in an experimental study under conditions resembling those of open heart operations in human beings. A more detailed analysis of the interaction between the biodegradable patch and epicardium should be considered with the enhanced inflammatory reaction induced by cardiopulmonary bypass and surgical trauma. Moreover, why could one not create biodegradable patches soaked in some antiinflammatory substances such as protease inhibitors that could attenuate postbypass inflammatory reactions?

On the basis of our preliminary clinical experience, the biodegradable patch seems to be an interesting material as a pericardial substitute in patients who might require reoperation in the medium or long term when primary pericardial closure is not possible.

\section{REFERENCES}

1. Malm T, Bowald S, Bylock A, Busch C. Prevention of postoperative pericardial adhesions by closure of the pericardium with absorbable polymer patches. J Thorac Cardiovasc Surg 1992;104:600-7.

2. Malm T, Bowald S, Bylock A, Saldeen T, Busch C. Regeneration of pericardial tissue on absorbable polymer patches implanted into the pericardial sac. Scand J Thorac Cardiovasc Surg 1992;26:15-21.

\title{
STERNAL HEMANGIOMA: A RARE TUMOR
}

Benjamin Medalion, MD, ${ }^{a}$ Ilan Bar, MD, ${ }^{a}$ Rami Neuman, MD, ${ }^{\mathrm{b}}$ Yaron Shargal, MD, ${ }^{\mathrm{a}}$ and Gideon Merin, MD, Jerusalem, Israel

Primary tumors of the bony chest wall are uncommon. ${ }^{1}$ Among those tumors, sternal tumors are extremely rare ${ }^{2}$ and usually malignant. ${ }^{2,3}$ In this case report, we discuss a benign hemangioma of the sternum in a 30 -year-old woman who had a 2-year history of chest pain without objective physical findings. She underwent a bone scan, with results regarded as normal. Computed tomography demonstrated a round mass in the body of the sternum (Fig. 1, $A$ ). On magnetic resonance imaging (Fig. 1, B), the mass was found to be located in the lower part of the sternal body to invade the sternal cortex. An open biopsy sampling of the mass was performed elsewhere, and a benign hemangioma was diagnosed. During the biopsy procedure, the patient had extensive bleeding, which was finally controlled.

Subsequent magnetic resonance imaging 2 months later demonstrated an enlargement of the mass, and she had an elective operation. The left and right internal thoracic arteries were divided at the manubrium. Each costochondral junction was divided on both sides after the intercostal vessels had been ligated and divided. The sternum was transected transversely through the second intercostal space; the resected sternum and the mass were then separated from the mediastinum and removed. The pec-

From the Departments of Thoracic and Cardiovascular Surgery ${ }^{\mathrm{a}}$ and Plastic Surgery, ${ }^{\mathbf{b}}$ Hadassah University Hospital, Jerusalem.

Received for publication Jan. 22, 1996; accepted for publication Feb. 8, 1996.

J Thorac Cardiovasc Surg 1996;112:1402-3

Copyright (C) 1996 by Mosby-Year Book, Inc.

$0022-5223 / 96 \$ 5.00+0 \quad \mathbf{1 2 / 5 4 / 7 2 6 6 1}$ toralis major muscles were mobilized and used as in situ flaps to close the wound.

The patient had uneventful operative and postoperative courses and went home 8 days after the operation. Histologic examination of the mass revealed an encapsulated $5 \times 5 \times 9 \mathrm{~cm}$ hemangioma that replaced almost the entire resected sternum. At 6-month follow-up the patient had regained a normal lifestyle, with no chest pain and no signs of recurrence.

A search of the literature revealed only one similar case, that of a 38-year-old woman who reported pain in the midanterior area of the chest. ${ }^{4}$ This patient had a history of similar intermittent pain for 15 years. Physical examination revealed only slight prominence and tenderness of the superior aspect of the sternal body. The patient underwent a surgical excision of the sternal lesion.

Benign sternal tumors are extremely rare, and all sternal tumors should be considered malignant until proved otherwise. ${ }^{4}$ Hemangiomas of the chest wall are most often encountered in the vertebra, ribs, and skeletal muscles. ${ }^{5}$ Although hemangiomas are quite common tumors, no hemangiomas of the sternum have been described except for the case published by Boker and coworkers ${ }^{4}$ and the case described here by us. Irradiation therapy, interferon therapy, and selective embolization of feeding vessels have been suggested as alternatives to surgical treatment, especially for children and patients with hemangiomas of the skin. ${ }^{6-8}$ Because there is no sharp distinction between benign hemangiomas and lowgrade malignant hemangioendotheliomas and because of the relatively high recurrence rate of hemangiomas, ${ }^{5}$ we decided to operate on this patient and to resect the tumor with adjacent sternal tissue. 

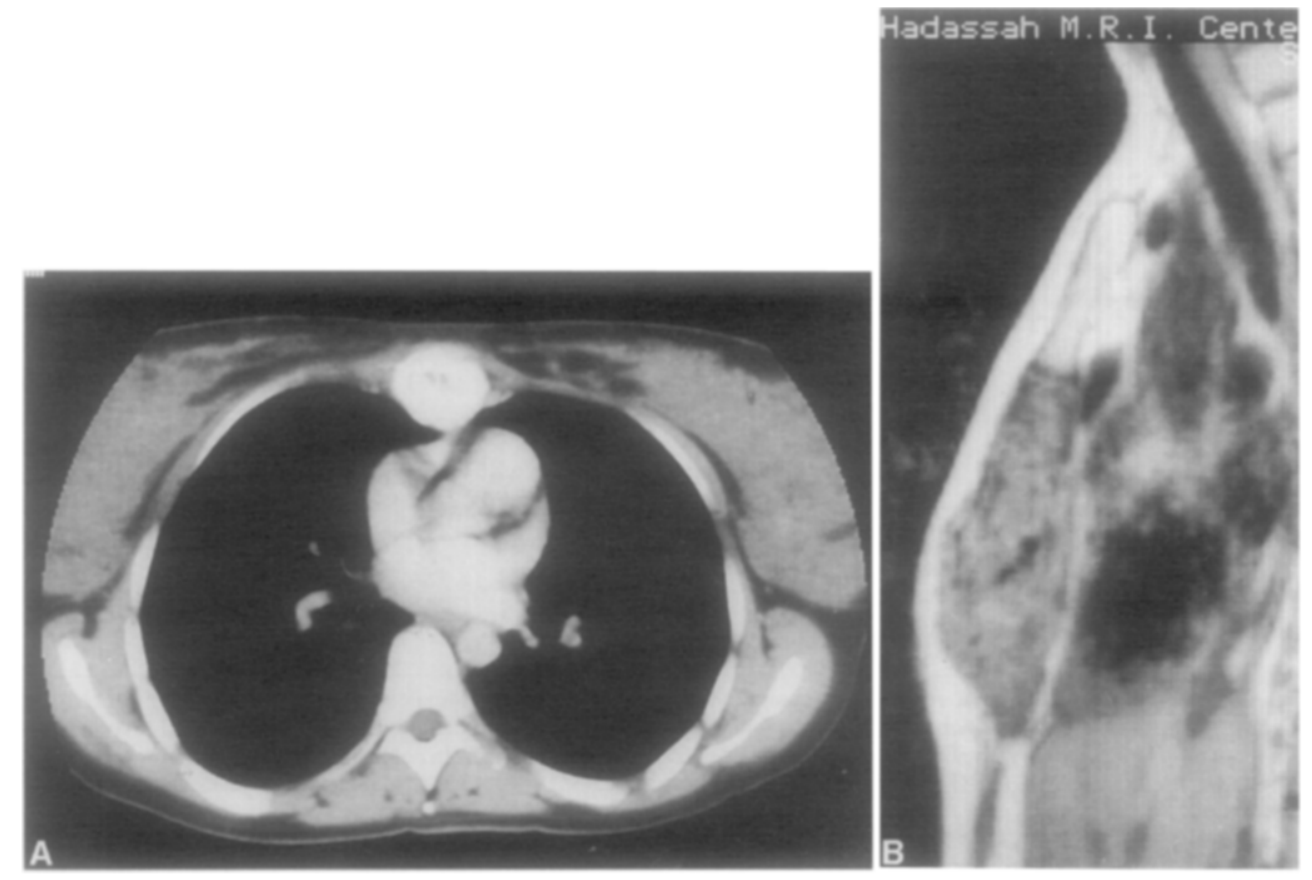

Fig. 1. A, Computed tomographic section of chest showing round mass in body of sternum. B, Longitudinal section of magnetic resonance image of chest showing mass located in lower part of sternal body and invading sternal cortex.

\section{REFERENCES}

1. Sabarantam S, Salama FD, Morgan WE, Harvey JA. Primary chest wall tumors. Ann Thorac Surg 1985;39:4-15.

2. Pascuzzi CA, Dahlin DC, Clagett OT. Primary tumors of the ribs and sternum. Surg Gynecol Obstet 1957;104:390.

3. Ochsner A Jr, Lucas GL, McFarland GB Jr. Tumors of the thoracic skeleton: review of 134 cases. J Thorac Cardiovasc Surg 1966;52:311-21.

4. Boker SM, Cullen GM, Swank M, Just JF. Case report 593: hemangioma of sternum. Skeletal Radiol 1990;19:77-8.
5. Faber LP, Somers J, Templeton AC. Chest wall tumors. Curr Probl Surg 1995;32:661-756.

6. Furst CJ, Lundell M, Holm LE. Radiation therapy of hemangiomas, 1990-1959: a cohort based on 50 years of clinical practice at Radiumhemmet, Stockholm. Acta Oncol 1987;26:33-6.

7. White $\mathrm{CW}$. Treatment of hemangiomatosis with recombinant interferon alfa. Semin Hematol 1990;27:15-22.

8. Trout HH. Management of patients with hemangiomas and arteriovenous malformations. Surg Clin North Am 1986;66: 333-8.

\title{
DIAGNOSTIC USE OF INHALED NITRIC OXIDE AFTER NEONATAL CARDIAC OPERATIONS
}

\author{
Ian Adatia, FRCP(C), Andrew M. Atz, MD, Richard A. Jonas, MD, and David L. Wessel, MD, Boston, Mass.
}

From the Departments of Cardiology and Cardiac Surgery, Children's Hospital, Pediatrics and Surgery, Harvard Medical School, Boston, Mass.

Received for publication April 18, 1996; accepted for publication April 24, 1996.

Address for reprints: Ian Adatia, $\mathrm{FRCP}(\mathrm{C})$, Cardiology and Critical Care Medicine, The Hospital for Sick Children, 555 University Ave., Toronto, M5G 1X8, Canada.

J Thorac Cardiovasc Surg 1996;112:1403-5

Copyright (C) 1996 by Mosby-Year Book, Inc.

$0022-5223 / 96 \$ 5.00+0 \quad \mathbf{1 2 / 5 4 / 7 4 3 3 3}$
The neonatal pulmonary vasculature may be extremely labile. Remodeling of the vessel wall, functional maturation of the endothelial cell, differentiation of the smooth muscle cell, release of vasoactive mediators, and vessel recruitment all contribute to the successful transition to a mature pulmonary circulation. ${ }^{1}$ In the child with pulmonary hypertensive congenital heart disease postnatal remodeling is abnormal. ${ }^{2}$ Even if a neonatal cardiac operation is undertaken, endothelium-dependent pulmonary vascular relaxation may be impaired after cardiopulmonary bypass and the postoperative course may be complicated by transient pulmonary hypertension. $^{3}$ 